\title{
Use of a disjunctive kriging to model areas of high pelagic fish density in acoustic fisheries surveys
}

Pierre Petitgas

ORSTOM, 72 roule d'A ulnay, 33143 Bondy cedex, France.

Received August Io, Igy2; accepted December 22, 1992.

Petitgas P. Aquat. Living Resour., 1993, 6, 201-209.

Abstract

Schooling fish may aggregate in very high densitics covering very small areas. Thus the probability of hitting such high-density spots during a large-scale sampling is very low. The sampling fluctuations of the tail of the histogram are thought to be very significant. The stock biomass estimate and its precision rely greatly on how prcciscly the tail of the histogram can be sampled. In order to acquire clements for improving survey designs and abundance estimators we study here the relation in space that the high values have with the other values. A disjunctive kriging approach is used. Different quantiles of the histogram are coded by indicators. The spatial structure of each indicator and its spatial covariation with the others are studied by computing experimental indicator variograms and cross-variograms. Such analysis is applied to dissect finely the spatial structure of a Norwegian herring stock sampled acoustically. It is shown that when going from low-density arcas to high-density ones, intcrmediate values are not necessarily crossed. Thus a particular disjunctive kriging model with no transition in space is well adapted to the herring data. The model is based on the regressions of each indicator on the one immediately below it. In the model one can estimate the probability for the fish density to trespass a given cut-off at a given location when knowing that the density trespasses lower cut-offs at surrounding points. It is shown on the data that the high densities are structured and show small aggregations. Then it is shown that having trespasscd a certain cut-off, i.e. inside the corresponding areas in space, the high-density aggregations can be considered to be positioned independently from the other values. These areas, where the structuring of the high values is not correlated to the structuring of the other values, are mapped using the fitted disjunctive kriging model. The implications for survey designing of the existence of such areas and of their geometry are discussed. Also discussed is the possibility of stratifying the data in spatially uncorrelated boxes when deriving the biomass estimate and its precision, on the basis of an observed spatial non-correlation property between the spatial distribution of different quantiles.

Keywords: Spatial distribution, aggregation, abundance estimation, geostatistics, sampling.

Un modèle de krigeage disjonctif pour caractériser les zones riches en poissons pélagiques dans les échantillonnages d'acoustique.

Résumé

Les poissons grégaires formant des bancs peuvent se présenter en de très fortes densités sur de petites surfaces. Lors d'un échantillonnage prospectif à large maille, la probabilité de rencontrer de tels gains riches est donc faible. Les fluctuations d'échantillonnage de la qucue de l'histogramme des densités sont supposées très importantes. L'estimateur d'abondance du stock et sa précision dépendent largement de la précision avec laquelle la queue de l'histogramme a pu être échantillonnée. Dans le but d'augmenter la précision de l'échantillonnage nous étudions les rclations structurales qu'entretiennent les fortes valeurs avec leurs voisines plus faibles. L'approche du krigeage disjonctif est mise à profit. Les quantiles de l'histogramme sont codés par des indicatrices; la structure spatiale de chaque indicatrice ainsi que sa covariation avec chacune des autres sont étudiécs en calculant des variogrammes 
simples et croisés. Il en résultc une dissection fine de la structurc spatiale. Cette méthodologie est appliquéc à un stock de hareng norvégien. On montre que partant des zones pauvres et cheminant vers les zones riches, on ne rencontre pas nécessairement des valeurs intermédiaircs. On choisit un modéle sans transition spatialc pour rendre compte de cctte caractéristique. Il est construit sur les régressions de chaque indicatrice sur l'indicatrice pour la coupure immédiatement inférieure. Dans le modèlc on peut estimer la probabilité pour que la densité dépasse un seuil donné en un point donné, sachant que ceile-ci dépasse des scuils inférieurs en des points proches. On montre sur les données que les fortes valeurs sont structurées dans l'espace et forment des agrégats. De plus, à l'intérieur des zones délinies par les valeurs supérieures à un certain scuil, les agrégats de forte densité peuvent être considérés comme implantés indépendamment des autres valeurs. Ces zones dans lesquelles la structuration des fortes valeurs n'cst pas corrélée à celles des autres, sont cartographićcs par krigcage disjonctif. On discute de l'importance de l'existence de telles zones et de lcur géométric pour définir un échantillonnage adapté. On discule aussi de la possibilité de stratifier les valeurs en lots indépendants pour estimer la biomasse ct sa précision après avoir observé la proprićté de non corrćlation précédentc.

Mots-clés : Distribution spatiale, agrégation, abondance, cstimation, géostatistique, échantillonnage.

\section{INTRODUCTION}

When at sea on an acoustic prospection cruise it is usual to sail through large areas very poor in data then encounter rich areas in which a few extreme very high values may sometimes be hit, apparently unexpectedly. If all locations of the fish habitat could be sampled at once, one would have access to the true regional histogram. From experience, having hit sometimes very high values, one may reasonably think that the regional histogram is very skew with a long tail, longer than a lognormal. As the few very high values sampled contribute the most in the estimation of total abundance of stock, it is very important to sample efficiently enough both their mean and their frequency. In spatial (i.e. sampling) terms, the problem is the following. Because of biological aggregation, the high densities develop on small areas. Are these sampled efficiently enough so as to give a precise image both of the spatial distribution and of the histogram? If not, the data will give an image too far from the reality and the statistics of the stock biomass assessment will be relevant to the data but not to reality.

This risk is great in pelagic assessments but there is a solution to reduce it. It is based on the analysis of the spatial structure. If the spatial distribution shows time invariant characteristics (for instance the location of the high-density areas are the same year after year) one may choose a sampling strategy for instance like stratified sampling which enables an over-sampling of the known rich zones in order to estimate with better precision the tail of the histogram. On the other hand, if the previous strategy is not possible because of time variability, then the nature of the acoustic survey is a prospection with the same sampling effort in all areas and there will be a risk of missing extremely high values while surveying. If this is the case, a model is needed to reconstruct the expected but unsampled tail of the histogram. Such a model must characterize how on average the high values are spatially related to the other ones. The purpose of the present study is to analyse on an example how the different ranges of values - high, medium, low, (i.e. the different quantiles of the histogram)-are related to each other in space. Results in this field are expected to lead to design of more efficient sampling strategies as well as to proposal of adequate non-linear estimators of abundance.

The non-linear disjunctive kriging approach is followed here. The spatial setting of the histogram quantiles is analysed and modelled. A test is presented and used to help in the choice between two classes of model: sailing from low-density areas, are high values encountered without going through intermediate values or must one sail through intermediate values before encountering the high ones? In the first case a model without transitions would be appropriate whereas in the second, the use of a diffusive model would be necessary. The disjunctive kriging model presented in this paper and fitted to acoustic densities of Norwegian herring has no transitions and is well adapted to characterize the very sharp transitions observed in the spatial distribution of fish density.

\section{METHODS}

\section{The data: biological aggregation and sampling effici- ency}

The present data set was proposed by Drs. I. Röttingen and K. Foote from the Marine Research Institute in Bergen (Norway) as a test data set for the 1991 ICES workshop on the "Applicability of spatial statistical techniques to acoustic şurvey data" (Anon., 1991). The surveyed area corresponds to one of the spawning grounds of the Norwegian herring stock. 
This stock is part of the arcto-herring group (Dragesund et al., 1980). The fish gather in this area for a few months. They do not show in-and-out migratory movements from the spawning ground once the spawning migration has ended. They are not thought to show large-scale movements on the spawning ground during the spawning season. Thus, during the spawning season, the large-scale spatial structure on the grounds is stable. The survey we deal with was undertaken in February 1990, after the spawning migration had occurred and it lasted 4 days. Thus, we may regard the data as an instantancous sample of a fixed spatial distribution. The data are acoustic backscattering of herring integrated along depth and along segments of one nautical mile along the ship's track (Elementary Sampling Distance Unit, ESDU). The integrated echoes are not converted into actual fish densities.

The acouslic prospective sampling and a proportional representation of the data are given in figure 1.

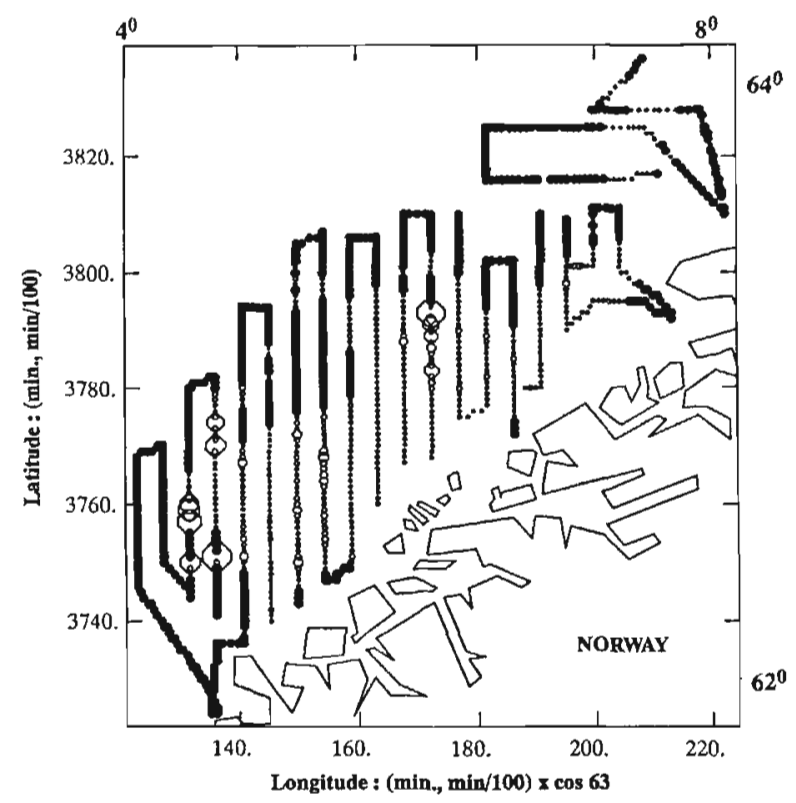

Figure 1. - Proportional representation of the data sampled during the survey of the Research Vessel "Eldjarn", Fcb. 1989 (Institute of Marine Research, Bergen, Norway).

The maximum value is represented by a circle of a fixed radius. The radii for the representation of all other values are deduced by proportionality of the values to their maximum. The zeros are shown by black discs. Their frequency in the total set is $52 \%$. They clearly define the limits of the area of fish presence and were sampled for this purpose. They do not represent holes of density inside the area of fish presence. The histogram of fish density was computed

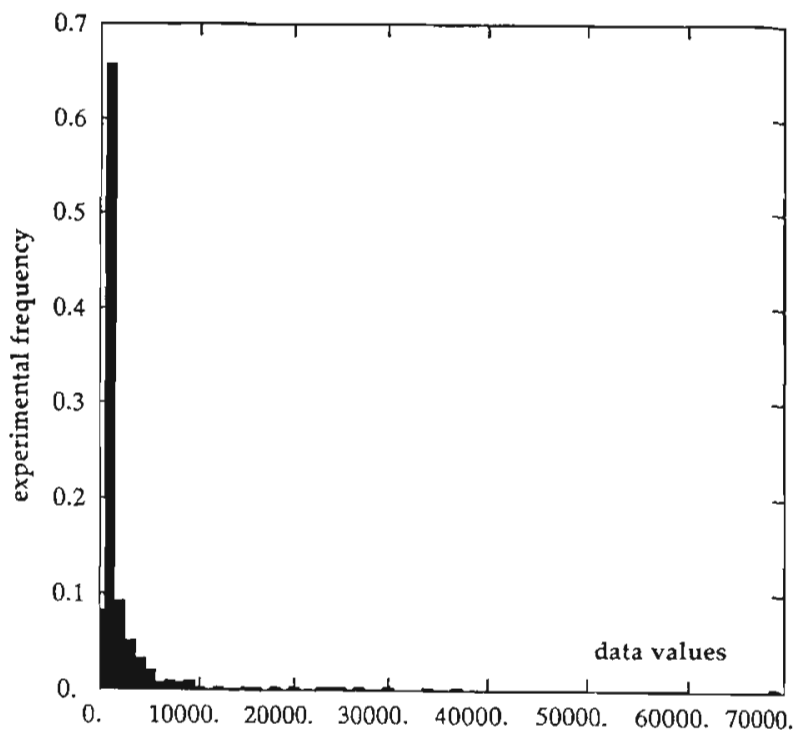

Figure 2. - Histogram of the non-zero values.

on the non-zero values (fig. 2). It is highly skewed; it shows a very long tail. Thus a reflection on the sampling efficiency of the tail of the histogram is justified.

The difficulty of estimating the total biomass is illustrated in figure 3 . The figure shows how much

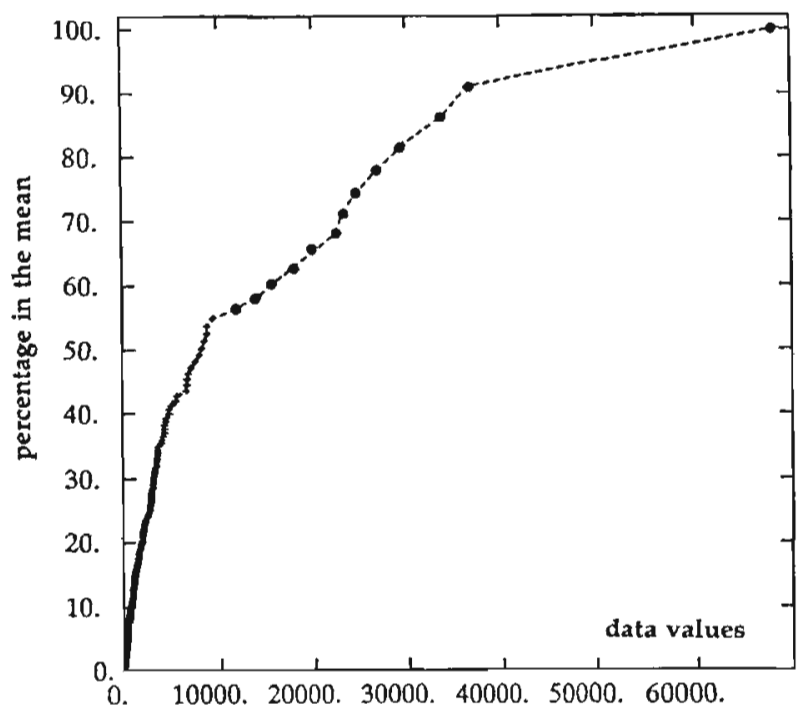

Figure 3. - Contribution to the arithmetical mean of each quantile.

each quantile of the ranked total data set contributes to the arithmetic mean of the data. The 13 highest values, those greater than $10^{4}$ backscattering units, represent only $3 \%$ of the total set but contribute $45 \%$ of the mean. They also contribute $90 \%$ of the variance of the data. The estimate and its precision are therefore highly dependent on the hit or miss of a few 
very high values. If the sampling effort or the sampling strategy are not well adapted to the spatial structure of the high values, these may not be hit during a given survey. In this case the data set will be too regular and the variance value misleading: one will think wrongly that the low biomass estimate is precise when this estimate is highly imprecise. We will now study how the high values are related to the other values in space.

\section{A disjunctive kriging approach: spatial relation between quantiles}

Each quantile of the histogram is coded by an indicator. Let us call $\mathrm{Z}(x)$ the Tish density at point $x$. The codification is:

$$
\begin{array}{ll}
1_{Z(x) \geqslant z}=1 & \text { if } Z(x) \geqslant z \\
I_{Z(x) \geqslant 2}=0 & \text { otherwise, }
\end{array}
$$

for any cut-off $z$. The cut-off $z$ defines in space geometrical sets referred to as $A_{Z}$ : inside them $Z(x)$ has values greater than $z\left(I_{Z(x) \geqslant z}=1\right)$; outside them $\mathrm{Z}(x)$ has values lower than $z\left(1_{Z(x) \geqslant z}=0\right)$.

We study the spatial setting of the sets defined by two different cut-offs, for all couples of cut-offs $\left(z, z^{\prime}\right)$. The spatial setting of the sets defined by two cut-offs $\left(z \leqslant z^{\prime}\right)$ can be described by a conditional probability. For instance,

$$
\mathrm{P}\left(\mathrm{Z}(x+h) \geqslant z^{\prime} / \mathrm{Z}(x)<z, \mathrm{Z}(x+h) \geqslant z\right)
$$

is the probability that when entering in the domain of the values greater than $z$, a value greater than $z^{\prime}$ is encountered. Rivoirard (1993) defined also another probability for a descending order of the cut-offs, but we shall only be concerned here with characterizing the spatial setting of the quantiles for cut-offs in an ascending order.

Assuming that the bivariate distribution $(\mathrm{Z}(x), \mathrm{Z}(x+h))$ is symmetrical, the conditional probability can be expressed in terms of indicator variograms. Let us denote $\gamma_{z}(h)$ the variogram of the indicator for the cutoff $z \cdot \gamma_{z}(h)$ quantifies the probability for a vector of length $h$ to have one extremity inside the set $A_{z}$ and the other one outside it:

$$
\begin{aligned}
\gamma_{z}(h)=\mathrm{P}(\mathrm{Z}(x) \geqslant z, \mathrm{Z}(x+h) & <z)=\gamma_{z}(-h) \\
= & \mathrm{P}(\mathrm{Z}(x)<z, \mathrm{Z}(x+h) \geqslant z) .
\end{aligned}
$$

Let us denote $\gamma_{z z^{\prime}}(h)$ the cross variogram between the two indicators for the cut-offs $z$ and $z^{\prime}\left(z \leqslant z^{\prime}\right) . \gamma_{z z^{\prime}}(h)$ quantifies the probability for a vector of length $h$ to have one extremity inside one of the sets and the other extremity outside the other set:

$$
\begin{aligned}
\gamma_{z z^{\prime}}(h)=\mathrm{P}\left(\mathrm{Z}(x) \geqslant z^{\prime}, \mathrm{Z}(x+h)<z\right)=\gamma_{z z^{\prime}}(-h) \\
=\mathrm{P}\left(\mathrm{Z}(x)<z, \mathrm{Z}(x+h) \geqslant z^{\prime}\right) .
\end{aligned}
$$

So we have:

$\mathrm{P}\left(\mathrm{Z}(x+h) \geqslant z^{\prime} / \mathrm{Z}(x)<z, \mathrm{Z}(x+h) \geqslant z\right)=\gamma_{z z^{\prime}}(h) / \gamma_{z}(h)$.

Rivoirard (1990, 1993) has characterized different types of model by the behaviour of the ratio $\gamma_{z z^{\prime}}(h) / \gamma_{z}(h)$. If it is constant with $h$, then the sets for the higher cut-off $\mathrm{A}_{\mathrm{Z}^{\prime}}$ are fitted inside the sets for the lower cut-off $A_{z}$ but there is no border effect. The sets for the higher cut-off are not necessarily in the middle of the sets for the lower cut-off. We are in a model showing no spatial transition. If the ratio increases with $h$, there is a border effect and we are in a diffusive model. So the computation of the indicator variograms and cross variograms serves as a test to characterize the spatial setting of the histogram quantiles. Such a test was used on the herring data.

\section{RESULTS}

\section{Fit of a model to the data}

\section{Adequacy of the model's geometrical properties to the data}

The different cut-offs used are chosen on a logarith. mic scale and are given in table 1 . The variograms of

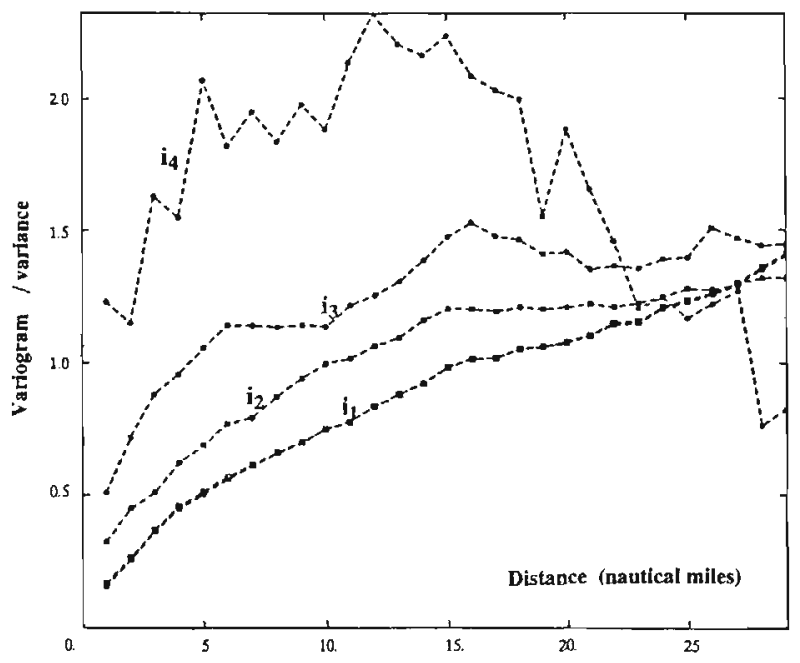

Figure 4. - Variograms of 4 indicators scalcd by their respective variances $\left(i_{k}(x)\right.$ is the indicator for the cut-off $10^{k}$ and n.m. stands for nautical milcs).

the indicators are shown on figure 4. They are all structured: this means that the values in each quantile are aggregated. The range of the variograms decreases when the cut-off increases (destructuration). Physically this means that the area of influence around each point gets smaller and smaller when the value at the point increases. The variogram ratios are given in figure 5. All curves have a similar behaviour. The ratio increases rapidly at short distance, between 0 

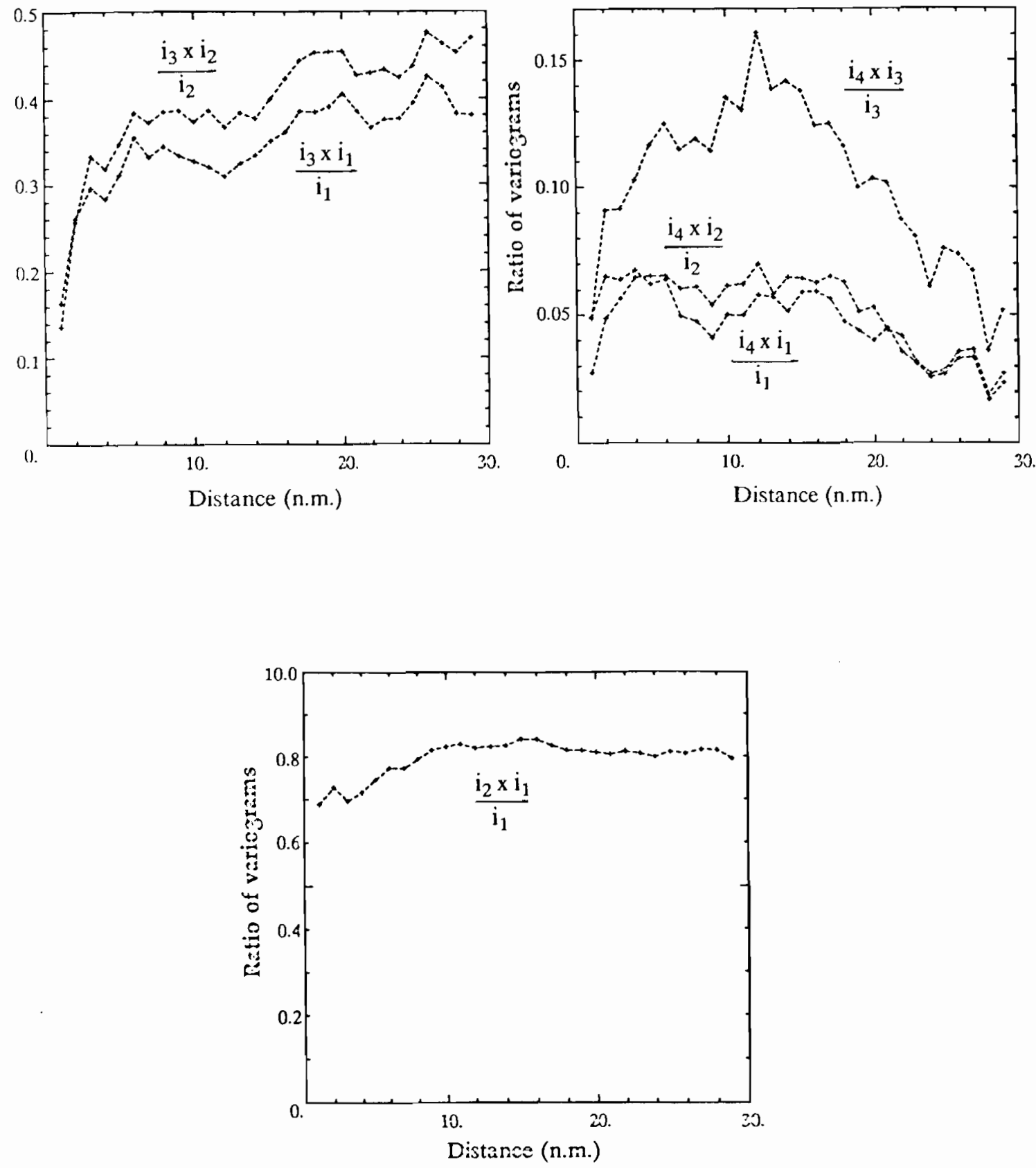

Figure 5. - Testing for the existence of border effects. Ratio of the cross-variogram between 2 indicators over the variogram of the indicator for the lower cut-off ( $i_{k}(x)$ is the indicator for the cut-off $10^{k}$ and $n . m$. stands for nautical miles).

and 3 nautical miles, then for greater distances it stabilizes. Thus there is a small border effect of a few nautical miles. When sailing a distance of a few miles, the fish density under the boat may change considerably, from one order of magnitude to another on a log scale. In comparison to the area surveyed, a few miles is very small. We therefore shall reglect the small border effset.
Takie 1. - Four cut-offs on a logarithmic scale and the experimental probability the fish density has of trespassing them ( $z$ represents the cut-off values, $Z$ represents the random function and $P$ represents the probability).

\begin{tabular}{lcccc}
$z$ & 10 & $10^{2}$ & $10^{3}$ & $10^{4}$ \\
$\mathrm{P}(\mathrm{Z}(x) \geqslant z)$ & 0.49 & 0.37 & 0.12 & 0.03 \\
\hline
\end{tabular}



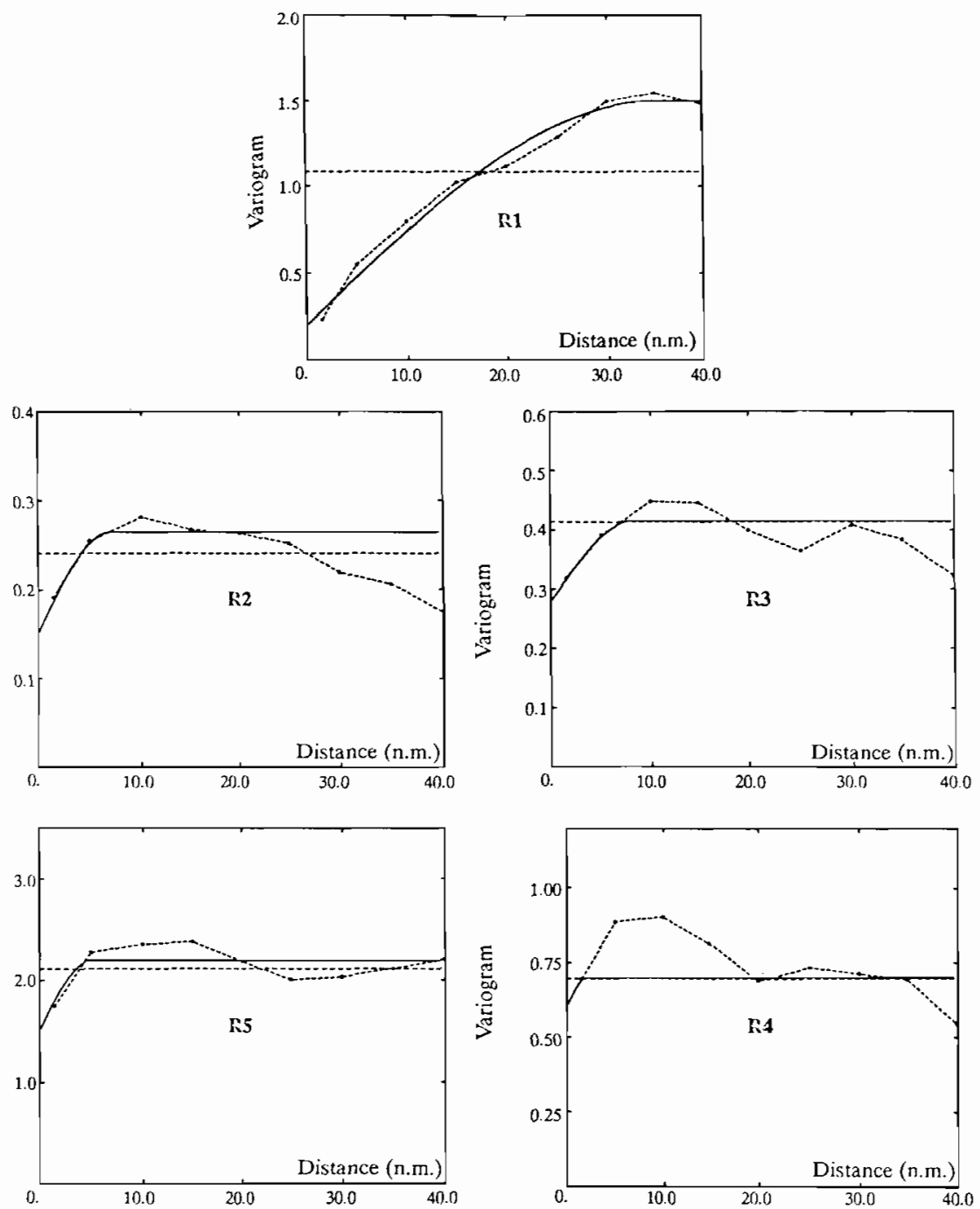

Fizare 6. - Variograms of indicator residuals, $R_{1}$ to $R_{5}$ (n.m. stands for nautical miles).

The data show two geometrical properties: destructuration of the sets with increasing cut-offs and no spatial transition between cut-offs. Thus the model with orthogonal indicator residuals (Rivoirard, 1989) is well adapted to describe the data. We shall now fit this model to the data and extract from it a quantitative description of the fine spatial structure.

\section{Fit of the model and inference of parameters}

The linear regression between an indicator for a high cut-off $z^{\prime}$ on the indicator for a low cut-off $z$ defines the conditional probability for $Z(x)$ to trespass $z^{\prime}$ when it is known that $Z(x)$ trespasses $z$. The residuals of such regressions play a crucial role in the model with orthogonal indicator residuals. The residuals are defined as follows:

$$
\mathrm{R}_{j}(x)=\frac{1_{\mathrm{Z}(x) \geqslant z_{j}}}{\mathrm{~T}_{j}}-\frac{1_{Z(x) \geqslant z_{j-1}}}{\mathrm{~T}_{j-1}}
$$

where $\mathrm{T}_{i}=\mathrm{P}\left(\mathrm{Z}(x) \geqslant z_{i}\right)=\mathrm{E}\left(\mathrm{l}_{\left.\mathrm{Z}(x) \geqslant z_{i}\right)}\right)$ and where $z_{j-1}$ and $z_{j}$ are 2 successive cut-offs in ascending order.
Rivoirard (1989) has shown that taking $n+1$ cutoffs on $Z(x)$, the $n+1$ residuals $\mathrm{R}_{0}(x)=1$, $\mathrm{R}_{1}(x), \ldots \mathrm{R}_{n}(x)$ are uncorrelated 2 by 2 and generate the $n+1$ indicators:

$$
\mathrm{J}_{Z(x) \geqslant z_{j}}=\mathrm{T}_{j} \sum_{i=0}^{j} \mathrm{R}_{i}(x) .
$$

The probability $T_{j}$ is known experimentally. The estimation of the indicator at an unsampled point $x_{0}$ varies from 0 to 1 and measures the conditional probability for $Z(x)$ to trespass $z_{\text {; }}$ when it is known at the sampled points what cut-oris $Z(x)$ trespasses. For estimating the indicator at $x_{0}$, it is sufficient to krige separately the $j$ residuals. The estimation of the indicator relies on the spatial structure of the residuals. For instance, suppose that the structure of the residual $\mathrm{R}_{p}(x)$ is a pure nugget effect. Its kriging equals its mean at $x_{0}$. Thus it is zero and the residual contributes nothing to the estimation of the indicator. 

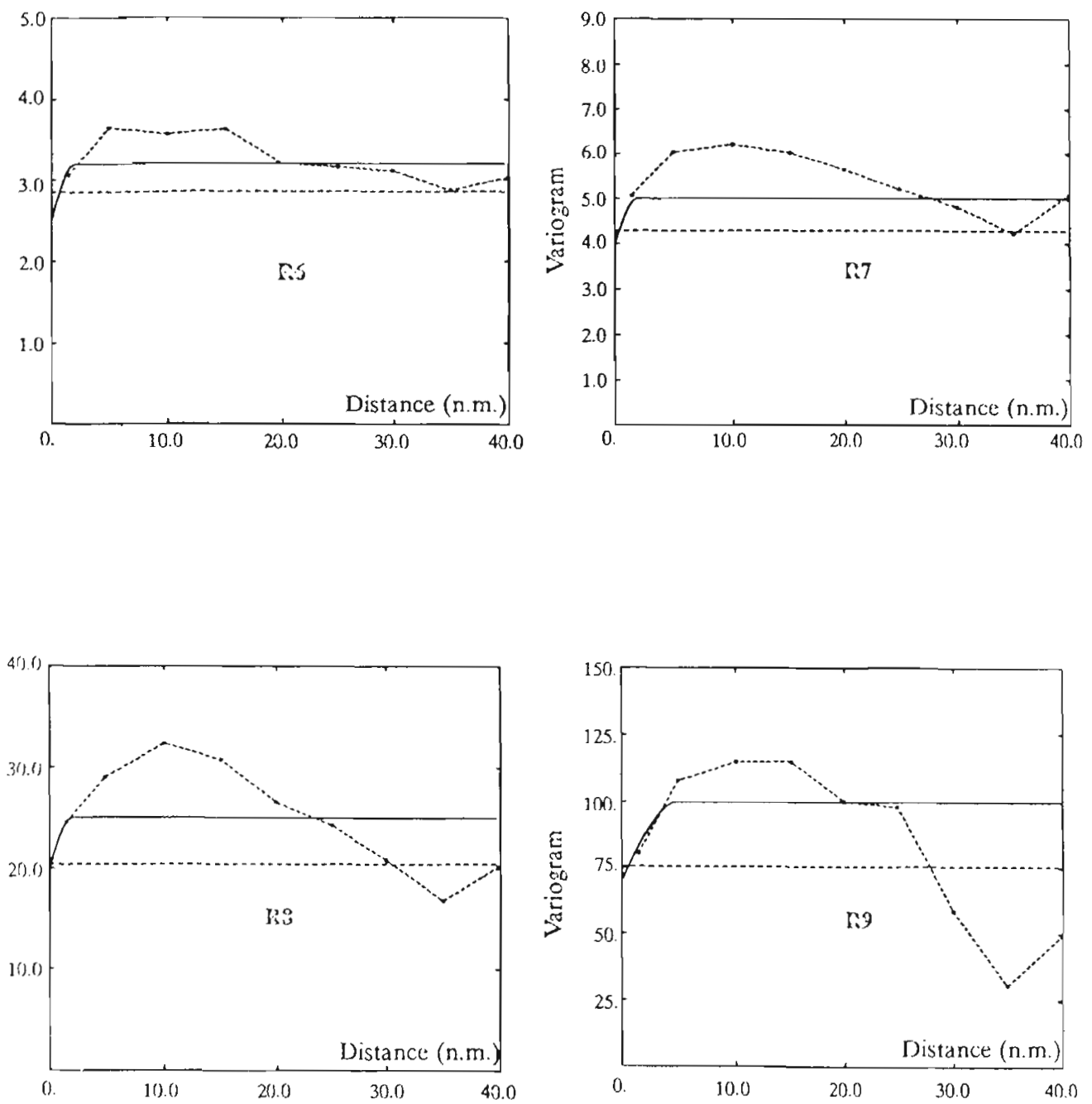

Fizare 7. - Variogram of indicator residuals, $R_{6}$ to $R_{9}$ (n.m. stands for natitical miles).

Talie 2. - Residuals of the linear regressions of indicators for successive cut-offs. $\mathrm{R}_{j}(x)$ is the residual of the regression of the indicator for the cut-off $z_{j}\left(1_{Z(x) \geqslant z_{j}}\right)$ on the indicator for the immediate lower cut-cff $z_{j-1}\left(l_{z(x) \geqslant z_{j-1}}\right)$.

\begin{tabular}{rrrrrrrrrr}
\hline $\mathbf{R}_{j}$ & $\mathbf{R}_{1}$ & $\mathbf{R}_{2}$ & $\mathbf{R}_{3}$ & $\mathbf{R}_{\mathbf{4}}$ & $\mathbf{R}_{5}$ & $\mathbf{R}_{6}$ & $\mathbf{R}_{7}$ & $\mathbf{R}_{8}$ & $\mathbf{R}_{9}$ \\
\hline$z_{j}$ & 10 & 50 & 100 & 200 & 500 & 1000 & 2000 & 5000 & 10000 \\
$z_{j-1}$ & 0 & 10 & 50 & 100 & 200 & 500 & 1000 & 2000 & 5000 \\
\hline
\end{tabular}

There is no spatial information in it for the prediction. We shall now focus on the structures of the residuals fitted on the data.

Ten cut-offs are considered on the histogram for fitting the model: $0,10,50,1 \mathrm{CO}, 2 \mathrm{CO}, 5 \mathrm{CJ}, 1 \mathrm{CO}, 2 \mathrm{C} 0$, $5000,10 \mathrm{cov}$. There are ten residuals, $\mathrm{R}_{0}(x)$ to $\mathrm{R}_{9}(x)$. They are given in table 2 . The variograms of the residuals $\mathrm{R}_{1}(x)$ to $\mathrm{R}_{9}(x)$ are computed along the transects and are shown on fizures 6 and 7 . The parameters of the fitted spherical models are given in

Trise 3. - Parameters of the spherical models fitted on the variograms of the residuals.

\begin{tabular}{lcccccccccc}
\hline \multicolumn{1}{c}{ Residual $\mathrm{r}_{j}$} & $\mathrm{r}_{\mathbf{1}}$ & $\mathrm{r}_{2}$ & $\mathrm{r}_{3}$ & $\mathrm{r}_{\mathbf{4}}$ & $\mathrm{r}_{5}$ & $\mathrm{r}_{6}$ & $\mathrm{R}_{7}$ & $\mathrm{r}_{8}$ & $\mathrm{R}_{9}$ \\
\hline Nugget $c_{0}$ & 0.20 & 0.50 & 0.28 & 0.60 & 1.50 & 2.50 & 4.00 & 20.00 & 70.00 \\
Sill $c$ & 1.30 & 0.12 & 0.14 & 0.10 & 0.70 & 0.70 & 1.00 & 5.00 & 30.00 \\
Range $(\mathrm{n.m})$ & 35 & 7 & 8 & 2 & 5 & 2 & 2 & 2 & 5 \\
$c_{0} /\left(c+c_{0}\right) \%$ & 13.3 & 81.3 & 67.5 & 85.7 & 63.2 & 78.1 & 80.0 & 80.0 & 70.0 \\
\hline
\end{tabular}




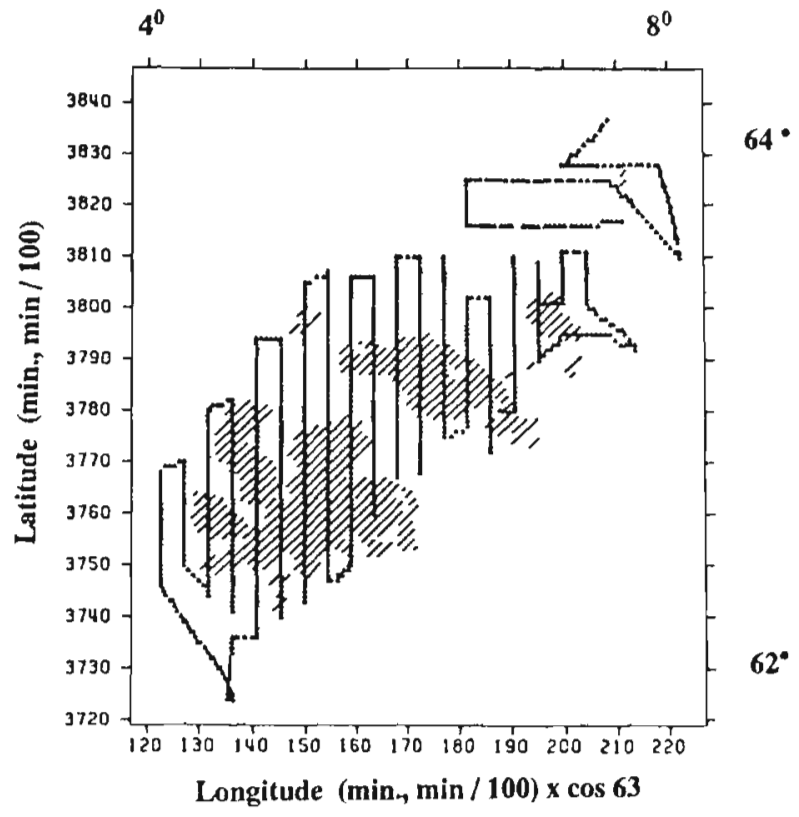

Figure 8. - Estimation by disjunctive kriging of the gcometrical scts defined by the cut-off 500 and representing the biomass orebody of herring.

table 3. The consistency of the different fits is discussed in Petitgas (1991) as the different models for the residuals are not independent from each other and must satisfy some relation. For the residuals $R_{1}$ to $R_{5}$, the variograms show a progressive destructuration (the range decreases and the sill increases). For the residuals $R_{6}$ to $R_{9}$, the variograms show a stabilization of their parameters: the range varies from 2 to 5 nautical miles, the nugget value stays near $80 \%$ of the variance. The residuals $R_{6}$ to $R_{9}$ are not very structured and we shall consider them to be pure nugget effects. Physically, this means that when entering the sets $A_{500}$ where the fish density is greater than 500 , it is not possible to predict where the fish density may trespass greater cut-offs nor to predict the value of the cut-off. The densities higher than $10^{4}$ arc a little aggregated (their indicator variogram is structured), they form small grains that are located independently from the other values within $\mathrm{A}_{500}$. On the other hand, the limits of $A_{500}$ may be estimated well because the residuals $R_{1}$ to $R_{5}$ are structured.

The values greater than 500 represent $90 \%$ of the herring biomass. The geometrical sets defined by the cut-off 500 correspond to what could be called the herring orebody. The geometry of the orebody may be predicted correctly from the sampled data, but not the local densities within it. Thus, the estimation of the mean density is imprecise. The indicator $l_{Z(x) \geq 500}$ was estimated by kriging and the geometrical sets $\mathrm{A}_{500}$ are represented in figure 8.

\section{DISCUSSION-CONCLUSION}

The quantiles of the herring histogram had a particular spatial setting that was well described by a model with orthogonal indicator residuals. The gcometrical sets defined by increasing cut-offs showed progressive destructuration. As the cut-offs increased, the sets were shown to be fitted in each other without border effects. High values could occur near low values without transition. The fit of the model revealed that once in the rich areas, one could no longer predict either the value the fish density could trespass or where this might happen. This result leads one to reflect on the need for an appropriate abundance estimator as well as for an appropriate survey design.

The previous analysis tells us that higher densities than the one sampled could have existed that were not sampled. Thus, if one takes the data arithmetical mean as an abundance estimate, the imprecision of this estimate could be far greater than the one that is computable from the data, as this estimate is very sensitive to the hit or miss of high values. Because the sampling fluctuations may be very high both on the frequency and on the values of the tail of the histogram, a model is needed to take into account the presence of high densities even if they were not sampled. It is thought that such a model would not only need to state how the high values are organized in space amongst the other values, but also would need to state a physical relation between histogram skewness and variogram destructurations.

As in the rich areas the high values are independently positioned from the other values, one is led to think that the high values may be treated separately from the rest of the values in the estimation method. Simmonds et al. (1991) discuss extensively the possibility to stratify the data on the data values themselves. This can be criticised as many classes will lcad to a zero variance for the estimate. Johannesson and Mitson (1983) had suggested that only a few classes be considered because they argued these would have an ecological meaning. We effectively observed here a spatial non-correlation property of the histogram tail which could justify stratification of the data using the sample values. Gerlotto and Stequert (1983) had uscd such characteristics for simulation purposes. From the present study, it is our thinking that the average biomass could be estimated in two steps: the mean of the histogram tail requires a model-based estimator whereas the mean of the other values can be estimated by a simple arithmetic mean.

If time-invariant characteristics of the spatial distribution can be cxhibited, these may serve for designing future surveys. The existence, the dimensions and the number of areas where high values occur unpredictably are thought to be important pieces of information. In the present case on Norwegian spring - spawning herring, there are three separate areas $(f i g .8)$ inside which the last quantile 
$\left(Z(x) \geqslant 10^{4}\right)$ is located independently from the others. These areas are of large dimensions and their cumulated surfaces represent $34 \%$ of the total area surveyed $\left(\mathrm{P}\left(\mathrm{Z}(x) \geqslant 10^{4}\right)=0.34\right)$. Thus the regular sampling design goes through them often and can be said to be adapted to the geometry of the interesting areas. Other stocks or the same stock during another season may show another spatial splitting of the areas where the high values occur independently from the others. These areas could be of small dimensions, there could be many or few. Such geometric disposition in space of the interesting areas to survey may require more adaptive sampling strategies.

The sampling effort in the interesting areas can be calibrated on the spatial structure of the high values which contribute the most to the biomass estimate. The variogram range of the indicator of the high values quantifies the mean width of the high-value aggregates. This parameter could serve to calibrate the sampling effort, i.e. the inter-transect distance. If the inter-transect distance approximates the range, all aggregates are theoretically visited by the sampling. Thus the tail of the histogram is better known. In the present case study, the inter-transect distance approximated the along transect range. After a discussion on anisotropy, the sampling was thought well adapted both to the structure and to the setting of the high values (Petitgas, 1991).

The geometrical properties of the fitted model could be general for pelagic fishes. It is indeed a general rule (Taylor, 1961) that for aggregated spatial distributions generating skewed statistical distributions like the ones we deal with, the local variance is a power function of the local mean. The fact that the last quantile appeared independently positioned from the others within specific arcas could be related to the fact that the local variance is very high in these areas, too high for one to detect correlation. It is possible that our result is a spatial way of expressing Taylor's power law. If so, one could in general be able to exhibit a cut-off $z$ and define areas where the last quantile appears uncorrelated to the others. A map of these interesting areas like figure 8 would serve to estimate the number of separated sets as well as their surfaces and thus help define an appropriate survey design.

Lastly, the existence of these areas where the high values occur in an aggregated fashion but without correlation with their surroundings leads one to interpret rich areas for pelagic fishes as areas where very high densities may occur, i.e. areas of potentially high densities, rather than areas where the fish density is on average high.

\section{Acknowledgements}

I wish to thank Drs. J. Rivoirard and K. Foote who give me support during this work. I am also indebted to Dr. G. Swartzman who helped improve the manuscript.

\section{REFERENCES}

Anon, 1991. Report of the workshop on the applicability of spatial statistical techniques to acoustic survey data. ICES/CIEM, CM 1991/D:40, 71 p.

Dragesund O., J. Hamre, O. Ulltang, 1980. Biology and population dynamics of the norwegian spring spawning herring. Rapp. P. V. Réun. Cons. Int. Explor. Mer., 177, 43-71.

Gerlotto F., B. Stequert, 1983. Une méthode de simulation pour étudier la distribution des densités en poissons: application à deux cas réels. FAO Fish. Rep., 300, 278-292.

Johannesson K. A., R. B. Mitson, 1983. Fisheries acoustics: a practical manual for biomass estimation. FAO Fish. Tech. Pap., 240, 249 p.

Petitgas P., 1991. Contributions gćostatistiques à la biologie des pêches maritimes. Thèse dr., École Nationale Supérieure des Mines de Paris, Paris, 211 p.
Rivoirard J., 1989. Models with orthogonal indicator residuals. In: Proc. Third International Geostatistical Congress, Geostatistics, Matheron G., M. Armstrong, eds., vol. 1, Kluwer Academic Press, 91-108.

Rivoirard J., 1990. Introduction to disjunctive kriging and to non linear geostatistics, course C-139, Centre de Géostatistique, Ecole Nationale Supérieure des Mines de Paris, 84 p.

Rivoirard J., 1993. Relation cntre les indicatrices attachées à une variable régionalisée, In: Proc. Fourth International Geostatistical Congress, Troja (Portugal) 1992, Kluwer Academic Press (in press).

Simmonds E. J., N. J. Williamson, F. Gerlotto, A. Aglen, 1991. Survey design and analysis procedures: a comprehensive review of good practice, ICES/CIEM, CM 1991/B:54, 113 p.

Taylor L. R., 1961. Aggregation, variance and the mean. Nature (London), 189, 732-735. 